\title{
Nova associação tonalítica-trondhjemítica neoarqueana na região de Canaã dos Carajás: TTGS com altos conteúdos de Ti, Zr e Y
}

\author{
Alan Cardek Brunelli Gomes ${ }^{1}$ \& Roberto Dall'Agnol ${ }^{2}$
}

\begin{abstract}
Resumo Uma Nova Associação Tonalítica-Trondhjemítica (ATTr) neoarqueana foi identificada na região de Canaã dos Carajás, no Domínio de Transição entre o Terreno Granito-Greenstone de Rio Maria (TGGRM) e a Bacia Carajás. Ela é formada por granitóides da série TTG, intrusivos em granitos potássicos de afinidade cálcio-alcalina, granitos alcalinos tipo-A, correlacionados ao Granito Planalto, e rochas vulcânicas do Supergrupo Itacaiúnas. Ela difere dos típicos granitóides da série TTG, inclusive daqueles do TGGRM, devido aos seus elevados conteúdos de Zr, Ti e Y. Além disso, contrasta com os últimos por pertencer ao grupo de TTG com baixo $\mathrm{Al}_{2} \mathrm{O}_{3}$. As rochas da ATTr exibem forte fracionamento de elementos terras raras pesados; os tonalitos mostram anomalias negativas de Eu incipientes ou moderadas, enquanto que os trondhjemitos exibem anomalias positivas de Eu. Sua gênese está relacionada ao importante evento datado em $\sim 2,75 \mathrm{Ga}$, responsável por intensa e diversificada geração de magmas na Bacia Carajás e no Domínio de Transição para o TGGRM, no final do Arqueano. Admite-se que o magma da ATTr derive da fusão parcial de gabros tholéticos continentais, cujo resíduo é composto por clinopiroxênio + plagioclásio \pm olivina. A hornblenda também pode ter influenciado a evolução deste magma, seja por sua retenção no resíduo de fusão, seja separando-se por processo de cristalização fracionada. $\mathrm{O}$ fracionamento de alanita poderia explicar as anomalias positivas de Eu, presentes em parte das amostras da ATTr.
\end{abstract}

Palavras-chave: tonalito-trondhjemito, arqueano, baixo $\mathrm{Al}_{2} \mathrm{O}_{3}$, Carajás, Cráton Amazônico.

\begin{abstract}
New early archean tonalitic-trondhjemitic association in the Canaã dos Carajás region: TTGS hight Zr, Ti, and Y contents. A new Early Archean Tonalitic-Trondhjemitic Association (ATTr) was identified in the Canaã dos Carajás region, in the Transition Domain between the Rio Maria Granite-Greenstone Terrane (RMGGT) and the Carajás Basin. This new TTG assemblage is intrusive in potassic calc-alkaline granites, A-type subalkaline granites, correlated to the Planalto Granite, and volcanic rocks of the Itacaiúnas Supergroup. The studied TTG display low $\mathrm{Al}_{2} \mathrm{O}_{3}$ and high $\mathrm{Zr}, \mathrm{Ti}$, and $\mathrm{Y}$ contents, differing in these respects from the most typical TTG granitoid series, including those of the RMGGT. All analysed rocks of the ATTr show strong fractionation of heavy rare earth elements; the tonalites display incipient or moderate Eu negative anomalies, while the trondhjemites show Eu positive anomalies. The ATTr was formed at $\sim 2.75 \mathrm{Ga}$ and is related to an important regional event responsible for intense magmatic activity in the Carajás Basin and in the Transition Domain of the RMGGT, at the end of the Archean. It is proposed that the magma of the ATTr derived from partial melting of continental tholeitic gabbros, leaving behind a residue composed of clinopyroxene + plagioclase \pm olivine. Hornblende also fractionated during the magma evolution, through its retention in the melting residue or by fractional crystallization. Allanite fractionation could be responsible for the positive Eu anomalies observed in some ATTr samples.
\end{abstract}

Keywords: tonalite-trondhjemite, TTG, Archean, low $\mathrm{Al}_{2} \mathrm{O}_{3}$, Carajás, Amazonian craton.

INTRODUÇÃo As rochas da série tonalito-trondhjemito-granodiorito (TTG) são dos principais componentes dos terrenos arqueanos. Em geral representam a primeira geração de granitóides, marcando o início da formação de crosta continental.

Os mecanismos normalmente aceitos para a produção das rochas da série TTG são: fusão parcial de basaltos tholeíticos de crosta oceânica, derivados do manto superior, previamente transformados em anfibolitos com granada (greenstone belts ou hornblenda eclogitos), relacionada à subducção em sistema de arco (Condie 1993, Martin 1994, Martin et al. 1997, Mar- tin 1999, Althoff et al. 2000) ou a eventos de tectônica vertical (sagducção; Choukroune et al. 1997, Leite et al. 2004). Mais recentemente, Condie (2005) concluiu que os "adakitos" são provavelmente fusões da crosta oceânica subductante, enquanto que os TTGs com altoAl seriam produto da fusão parcial da crosta inferior em sistema de arco ou nas zonas de raiz de platôs oceânicos.

No Terreno Granito-Greenstone de Rio Maria (TGGRM), sul da Província Mineral de Carajás, o Tonalito Arco Verde (Althoff et al. 2000), Complexo Tonalítico Caracol (Leite et al. 2004), trondhjemitos 
Mogno (DOCEGEO 1988) e Água Fria (Leite et al. 2004) são exemplos típicos de rochas arqueanas da série TTG. No Domínio de Transição entre o TGGRM e a Bacia Carajás (Dall'Agnol et al. 1997), também chamado de Domínio Imbricado do Cinturão de Cisalhamento Itacaiúnas (Araújo \& Maia 1991, Araújo et al. 1994, Costa et al. 1995), só havia sido individualizados em trabalhos anteriores os complexos Pium e Xingu e os granitos da Suíte Plaquê (Araújo \& Maia 1991) e Granito Planalto (Huhn et al. 1999). Com base em feições de campo e petrográfica, Araújo \& Maia (1991) e Lima (2002) descrevem rochas dominantemente tonalíticas, com trondhjemitos e granodioritos associados, como parte do Complexo Xingu. Entretanto, os dados geoquímicos disponíveis, até o momento, são muito limitados, não permitindo caracterizar estas rochas como pertencentes à série TTG. Além disso, não se dispõem de idade das mesmas.

Em virtude da carência de informações sobre as rochas pertencentes à série TTG, assim como outros granitóides, presentes no Domínio de Transição entre o TGGRM e a BC, onde está inserida a região de Canaã dos Carajás, é provável que o Complexo Xingu corresponda a uma associação de unidades ainda não individualizadas e não a um verdadeiro complexo, tal como se verificou no TGGRM (Dall'Agnol et al. 1997). Os resultados obtidos no mapeamento realizado no presente trabalho e outros ora em desenvolvimento na região de Canaã dos Carajás indicam claramente que estudos mais detalhados permitirão distinguir diferentes unidades nos domínios do atual Complexo Xingu, podendo levar ao desaparecimento desta unidade.

Com intuito de contribuir no entendimento da geologia do Domínio de Transição entre o TGGRM e a Bacia Carajás serão discutidos neste trabalho aspectos da geologia, petrografia e geoquímica da associação tonalítica-trondhjemítica (granitóides da série TTG), presente na região de Canaã dos Carajás. A associação estudada será também comparada com outras suítes TTG presentes na Província Mineral de Carajás.

CONTEXTO GEOLÓGICO REGIONAL A Província Mineral de Carajás (PMC) é considerada uma das mais importantes províncias metalogenéticas do mundo, com uma grande diversidade de depósitos minerais (DOCEGEO, 1988). Dados geocronológicos estabelecem idade arqueana para a PMC (Machado et al. 1991, Pimentel \& Machado 1994, Macambira \& Lafon 1995, Macambira \& Lancelot 1996, Dall'Agnol et al. 1999, Huhn et al. 1999, Rolando \& Macambira 2003, Leite et al. 2004).

Segundo Souza et al. (2001), a PMC é dividida em dois domínios tectônicos: (1) Terreno GranitoGreenstone Rio Maria (TGGRM), ao sul, e (2) Bacia de Carajás (BC), ao norte. Araújo \& Maia (1991), seguidos por Araújo et al. (1994) e Costa et al. (1995) propuseram, por sua vez, a denominação de Cinturão de Cisalhamento Itacaiúnas para a porção norte da PMC, ao passo que na parte sul estariam situados o Terreno Granito-Greenstone de Rio Maria e o Cinturão de Cisa- lhamento Pau D'Arco. Dall'Agnol et al. (1997) e Althoff et al. (2000) consideram, no entanto, que o TGGRM se estende até a região de Redenção. Essa interpretação foi reforçada em trabalhos mais recentes (Rolando \& Macambira 2003, Rolando et al. 2004), em que este limite foi estendido até a região da Serra do Inajá, não se reconhecendo, portanto, a existência de um domínio tectônico diferenciado correspondente ao Cinturão de Cisalhamento Pau D'Arco (Fig. 1).

O limite entre o TGGRM e a BC ainda é objeto de controvérsias (Costa et al. 1995, Souza et al. 2001, Dall'Agnol et al. 1997). Costa et al. (1995) situam o limite entre o Cinturão de Cisalhamento Itacaiúnas e o TGGRM imediatamente a sul de Xinguara, enquanto Souza et al. (1996) estimam que o mesmo localiza-se a norte da faixa de greenstone belt de Sapucaia. Dall'Agnol et al. (1997), por sua vez, sugerem que o terreno situado entre Xinguara e o sul da Serra dos Carajás (Bacia de Carajás) seria a zona de transição entre estes dois domínios tectônicos. Os estudos desenvolvidos por Leite et al. (2004) indicam que esta zona de transição situa-se a norte de Xinguara, pois os terrenos arqueanos desta região fazem parte do TGGRM (Fig.1).

O TGGRM é um típico terreno granito-greenstone arqueano formado por greenstone belts, enquadrados no Supergrupo Andorinhas (2979 \pm 5 Ma, Pimentel \& Machado 1994; 2971 18 Ma, Macambira \& Lafon 1995), uma série TTG mais velha composta pelo Tonalito Arco Verde $(2957+25 /-21$ Ma, Macambira \& Lancelot 1996; 2988 \pm 5 Ma, Rolando \& Macambira 2003) e Complexo Tonalítico Caracol (2948 \pm 5 Ma, Leite et al. 2004) e a mais nova formada pelos trondhjemitos Mogno (2871 \pm ? Ma, Pimentel \& Machado 1994) e Água Fria (2864 $\pm 21 \mathrm{Ma}$, Leite et al. 2004), granitóides sanukitóides alto $\mathrm{Mg}$ tipo Granodiorito Rio Maria (2872 \pm 5 Ma, Pimentel \& Machado 1994; 2878 4 Ma, Dall'Agnol et al. 1999; 2881 \pm 8 Ma, Rolando \& Macambira 2003), e leucogranitos potássicos de afinidade cálcio-alcalina tipo Granito Xinguara $(2865 \pm 1 \mathrm{Ma}$, Leite et al. 2004). Estas rochas estão recobertas pelos sedimentos do Grupo Rio Fresco (DOCEGEO 1988) e no Paleoproterozóico ocorreu a intrusão dos granitos anorogênicos do tipo-A da Suíte Jamon (1883+5/-2 Ma,

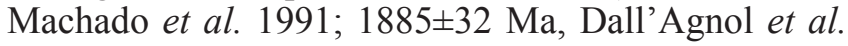
1999).

O embasamento da Bacia Carajás e do Domínio de Transição, entre esta bacia e o TGGRM, é formado pelos complexos Pium (3002 \pm 14 Ma, Pidgeon et al. 2000) e Xingu (2859 $\pm 2 \mathrm{Ma}$, Machado et al. 1991). As rochas supracrustais do Supergrupo Itacaiúnas (2732 \pm 3

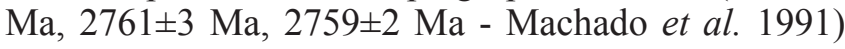
formam o preenchimento da Bacia Carajás. O magmatismo máfico-ultramáfico é representado pelo complexo Luanga (2763 \pm 6 Ma, Machado et al. 1991). Estas unidades são recobertas pelas rochas sedimentares da Formação Águas Claras (Araújo \& Maia 1991, Nogueira 1995, Pinheiro 1997). Com idade de 2736 $\pm 24 \mathrm{Ma}$ (Avelar et al. 1999), se encontram os granitos tipo-S da Suíte Plaquê, restritos ao Domínio de Transição 


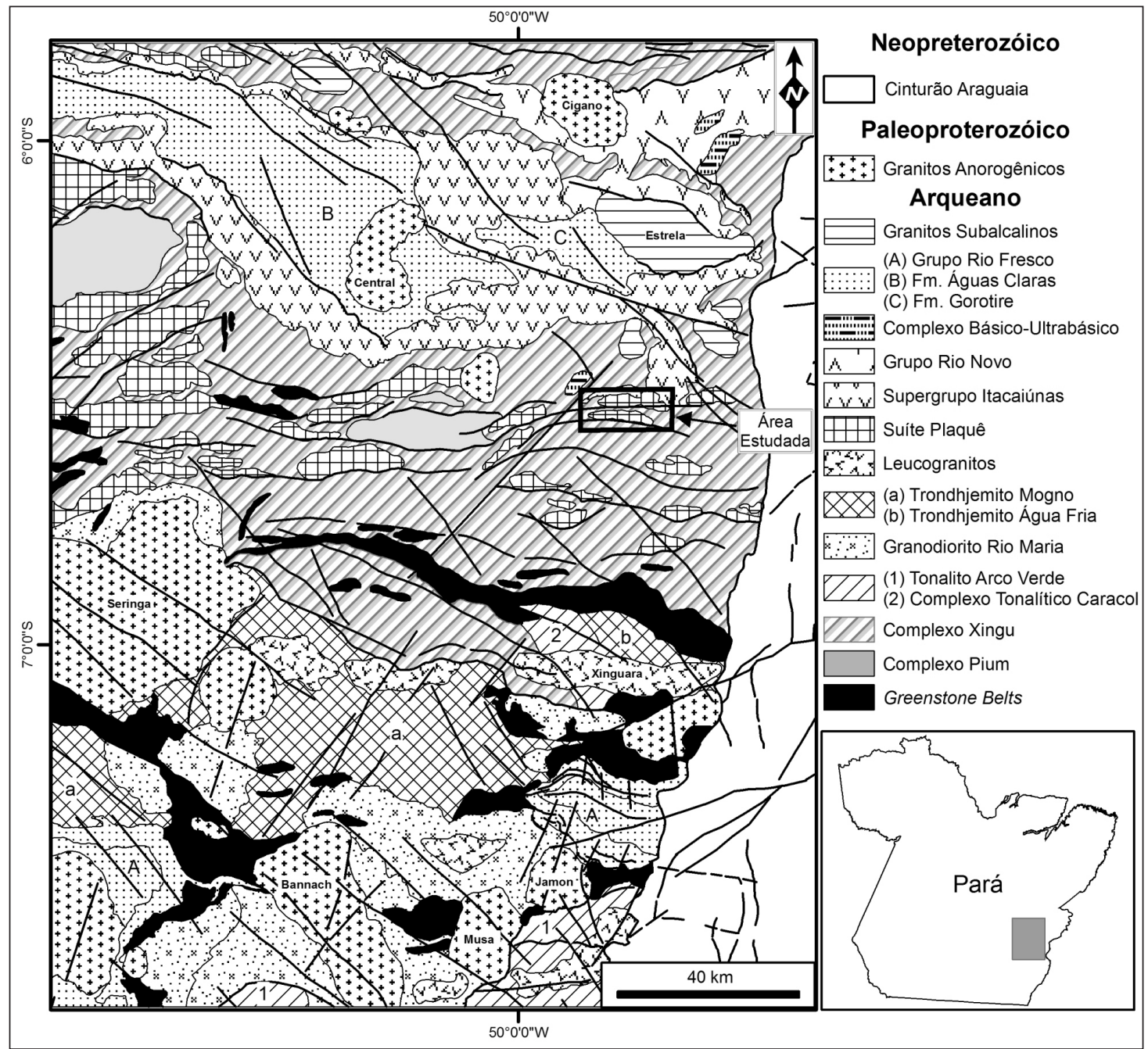

Figura 1 - Mapa simplificado da Província Mineral de Carajás (modificado de CPRM 2004).

(Araújo \& Maia 1991). Granitos subalcalinos tipo-A, subdivididos em mais antigos - Complexo Granítico Estrela (2763 $\pm 7 \mathrm{Ma}$, Barros et al. 2001), granitos Serra do Rabo (2743 $\pm 1,6$ Ma, Sardinha \& Barros 2002) e Planalto $(2747 \pm 2 \mathrm{Ma}$, Huhn et al. 1999; 2734 $\pm 4 \mathrm{Ma}$, Sardinha et al. 2004) - e mais jovens - tipo Old Salobo $(2573 \pm 2 \mathrm{Ma}$, Machado et al. 1991), ocorrem tanto na Bacia Carajás como no Domínio de Transição. No Paleoproterozóico ocorreu o magmatísmo gerador dos granitos anorogênicos, similares aos do TGGRM, aqui representados pela Suíte Serra dos Carajás $(1880 \pm 2$, Machado et al. 1991). As rochas sedimentares da Formação Gorotire recobrem as rochas mencionadas (Pinheiro 1997, Lima \& Pinheiro 2001, Lima 2002).

\section{GEOLOGIA DA REGIÃO A LESTE DE CANÃ̃} DOS CARAJÁS Gomes (2003) identificou na região a leste de Canaã dos Carajás (Fig. 2) rochas supracrustais (Supergrupo Itacaiúnas), rochas básicas, granitóides variados e coberturas lateríticas. Dentre as rochas básicas foram distinguidos anfibolitos e gabros (deformados e não deformados). Os granitóides foram divididos em quatro grupos: granitóides indiferenciados, leucomonzogranitos potássicos de afinidade cálcio-alcalina (2928 \pm 1 Ma, Sardinha et al. 2004), grani- tos subalcalinos do tipo-A ( $2734 \pm 4 \mathrm{Ma}$, Sardinha et al. 2004), correlacionados ao Granito Planalto, e Associação Tonalítica-Trondhjemítica (2750 3 Ma e $2765 \pm 39$ Ma, Sardinha et al. 2004).

Dentre os granitóides presentes nesta área (Fig. 2), as rochas da Associação Tonalítica-Trondhjemítica ocupam a menor área. No sul elas afloram formando morros alinhados, onde estão associadas às rochas do Granito Planalto. Neste domínio, a ATTr e o Granito Planalto eram cartografados como Suíte Plaquê (Araújo \& Maia 1991, Lima 2002). No noroeste da área mapeada a ATTr aflora num vale entre os morros do Granito Planalto e do Supergrupo Itacaiúnas e era cartografada como Complexo Xingu (Araújo \& Maia 1991, Lima 2002).

A ATTr é formada por rochas que variam de tonalito a trondhjemito. Na parte sul estas rochas são bastante deformadas, apresentando bandamento magmático de direção próxima de E-W, com alternância de bandas tonalíticas e trondhjemíticas, decimétricas a métricas e uma foliação subvertical de direção E-W. Nesta área está em contato com granitóides indiferenciados e Granito Planalto. No noroeste da área, as rochas da ATTr são menos deformadas, predominando textura isotrópica, com domínios tonalíticos intercalados com 


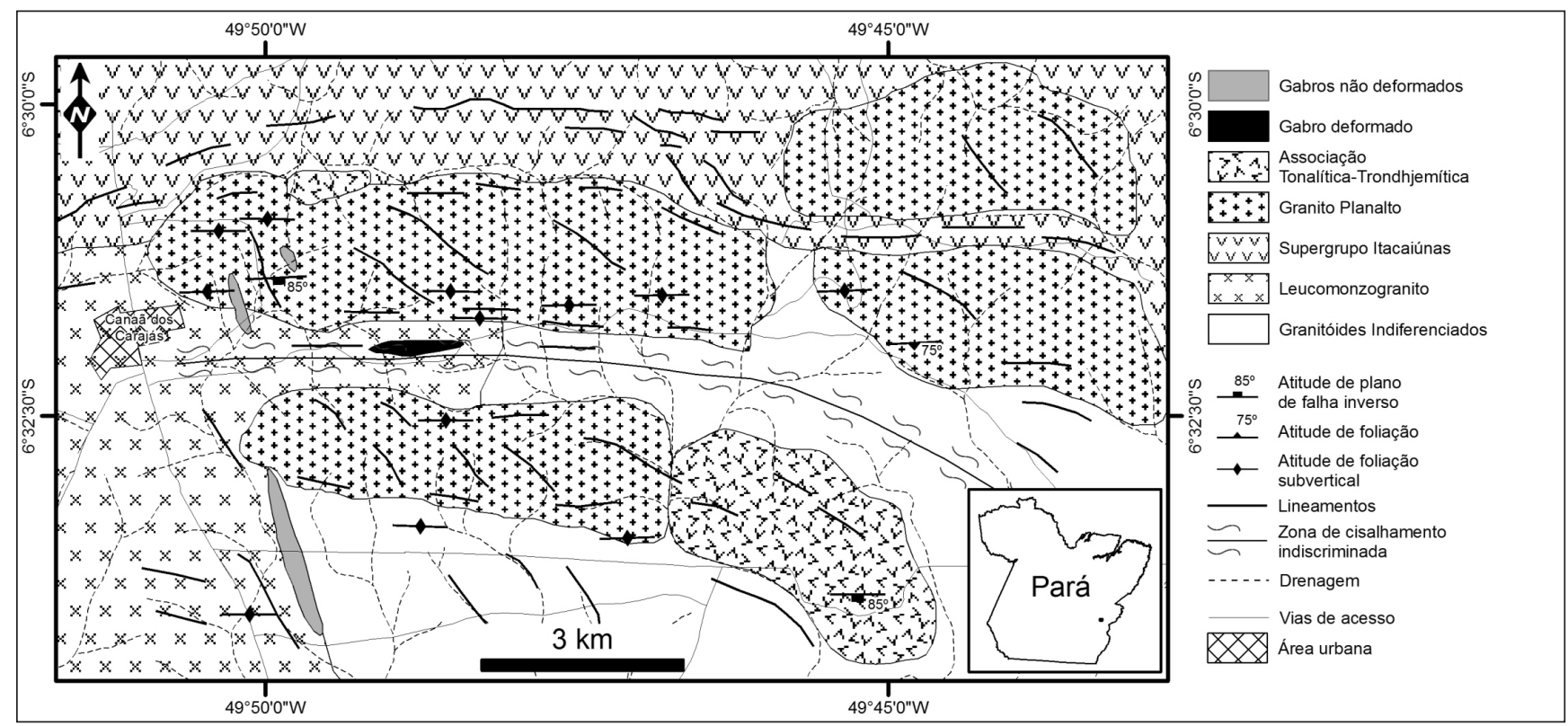

Figura 2 - Mapa geológico da porção E da região de Canaã dos Carajás.

domínios trondhjemíticos, em contato com rochas do Granito Planalto e do Supergrupo Itacaiúnas. Admitese que a ATTr seja intrusiva nas unidades mencionadas, embora as relações de campo não sejam inteiramente conclusivas.

Durante sua colocação, a ATTr, no domínio sul, foi submetida a esforço compressional de direção próxima a N-S, que gerou o bandamento magmático e foliação vertical com direções próximas de $\mathrm{E}-\mathrm{W}$, concordantes com o trend regional. Esta deformação ocorreu em estágio dúctil. Entretanto, a presença de planos de falha inversa com alto mergulho para SSE, que truncam a foliação primária, indica a ação de um esforço compressivo, de direção próxima a N-S, já no estágio rúptil. A presença de deformação no estágio dúctil e a idade obtida para a ATTr possibilita relacionar sua colocação com a fase de desenvolvimento de cisalhamentos regionais que afetou a Bacia Carajás correspondente ao Cinturão de Cisalhamento Itacaiúnas, mais precisamente ao Domínio Imbricado descrito por Araújo \& Maia (1991), sem registro expressivo no TGGRM. Os planos de falha inversa são interpretados como resultantes da reativação deste cinturão.

PETROGRAFIA As composições modais das amostras da ATTr (Tab. 1) revelam que os tonalitos possuem maior variação nos conteúdos de minerais máficos, destacam-se anfibólio, titanita e clinopiroxênio. Tanto eles quanto os trondhjemitos apresentam proporções modais muito reduzidas de feldspato alcalino. Os trondhjemitos são muito pobres em máficos $(\leq 2 \%)$, entre os quais predomina geralmente a biotita (Fig. 3). Tais composições permitem correlacionar a ATTr à serie cálcio-alcalina trondhjemítica-tonalítica de baixo potássio (Lameyre \& Bowden 1982). Reforça esta correlação o fato de a ATTr ser análoga ao Tonalito Arco Verde (Althoff et al. 2000) e ao Complexo Tonalítico Caracol (Leite et al. 2004), presentes no Terreno Granito-Greenstone de Rio
Maria e considerados como exemplos de granitóides arqueanos típicos da série TTG. Entre os contrastes petrográficos observados entre a ATTr e os granitóides TTGs mencionados, destacam-se a dominância de anfibólio e os altos conteúdos modais de quartzo verificados na primeira, e a ausência de termos granodioríticos.

$\mathrm{O}$ esforço que atuou sobre as rochas da ATTr tende a produzir uma orientação mineral, que não é necessariamente acompanhada de deformação dos cristais. Isto indica que durante a atuação do esforço havia coexistência de cristais e líquido (crystal mush).

GEOQUÍMICA Foram analisadas 14 amostras representativas da Associação Tonalítico-Trondhjemítica, distribuídas entre os corpos norte e sul da área (Tab. 2). Tais análises foram realizadas no Laboratório da Lakefield Geosol, pelos métodos de fluorescência de raios-X (elementos maiores e menores) e espectometria de massa por plasma induzido-ICP/MS (elementos terras raras). As determinações de $\mathrm{FeO}$ foram realizadas no Laboratório de Análises Químicas do Centro de Geociências da UFPA, seguindo a metodologia de via úmida por titulação com dicromato de potássio.

Os tonalitos da ATTr são metaluminosos e os trondhjemitos são peraluminosos (Fig. 4a), conforme mostra diagrama baseado no índice de Shand (Maniar \& Piccoli 1989). No diagrama normativo An-Ab-Or as amostras ocupam os campos correspondentes aos tonalitos e trondhjemitos (Fig. 4b), tal como ocorre com as típicas séries TTG. No diagrama $\mathrm{K}_{2} \mathrm{O} v s . \mathrm{SiO}_{2}$ (Fig. 4c) as amostras da ATTr ocupam, exclusivamente, o campo das rochas de baixo $\mathrm{K}_{2} \mathrm{O}$ e no diagrama $\mathrm{K}_{2} \mathrm{O}-\mathrm{Na}_{2} \mathrm{O}-$ $\mathrm{CaO}$ (Fig. 4d) acompanham o trend trondhjemítico, conseqüência dos seus baixos conteúdos de $\mathrm{K}_{2} \mathrm{O}$, distinguindo-se das rochas da série cálcio-alcalina clássica. Estas características, associadas ao seu baixo conteúdo de $\mathrm{Al}\left(\mathrm{Al}_{2} \mathrm{O}_{3}<15 \%\right.$ para $\left.\mathrm{SiO}_{2}=70 \%\right)$, revelam que a ATTr pertence à série dos granitóides TTG de baixo-Al, 
Tabela 1 - Composições modais da Associação Tonalítica-Trondhjemítica de Canaã dos Carajás.

\begin{tabular}{|c|c|c|c|c|c|c|c|c|c|c|c|c|c|}
\hline \multirow{3}{*}{$\begin{array}{l}\text { Corpo } \\
\text { Variedades } \\
\text { Amostras }\end{array}$} & \multicolumn{8}{|c|}{ Corpo do Norte da Área } & \multicolumn{5}{|c|}{ Corpo do Sul da Área } \\
\hline & \multicolumn{5}{|c|}{ Tonalito } & \multicolumn{3}{|c|}{ Trondhjemito } & \multicolumn{2}{|c|}{ Tonalito } & \multicolumn{3}{|c|}{ Trondhjemito } \\
\hline & $\begin{array}{l}\text { AMR } \\
124 \mathrm{~A}\end{array}$ & $\begin{array}{l}\text { AMR } \\
122 \mathrm{C}\end{array}$ & $\begin{array}{c}\text { AMR } \\
121 D^{*}\end{array}$ & $\begin{array}{c}\text { AMR } \\
123\end{array}$ & $\begin{array}{c}\text { AMR } \\
121 \mathrm{~A}\end{array}$ & $\begin{array}{l}\text { AMR } \\
124 \mathrm{~B}\end{array}$ & $\begin{array}{c}\text { AMR } \\
121 E^{*}\end{array}$ & $\begin{array}{c}\text { AMR } \\
126 \mathrm{~A}\end{array}$ & $\begin{array}{c}\text { AER } \\
68\end{array}$ & $\begin{array}{c}\text { AER } \\
71 \mathrm{C}\end{array}$ & $\begin{array}{c}\text { AMR } \\
191 A^{*}\end{array}$ & $\begin{array}{c}\text { AER } \\
70\end{array}$ & $\begin{array}{c}\text { AER } \\
69 \mathrm{~B}\end{array}$ \\
\hline Quartzo & 21,20 & 20,40 & 35,00 & 33,60 & 30,80 & 33,40 & 34,70 & 53,00 & 34,99 & 42,38 & 44,90 & 45,55 & 46,57 \\
\hline Plagioclásio & 32,00 & 46,60 & 32,70 & 41,50 & 50,00 & 64,50 & 63,90 & 43,70 & 50,12 & 44,42 & 52,00 & 52,62 & 50,84 \\
\hline Microclínio & 0,05 & 0,05 & 0,20 & 0,05 & 0,10 & 0,70 & 0,60 & 1,20 & 0,80 & 0,05 & 2,00 & 0,32 & 0,68 \\
\hline Hornblenda & 45,10 & 31,10 & 26,30 & 22,50 & 15,30 & $<0,05$ & $<0,05$ & $<0,05$ & 12,83 & 11,56 & $<0,05$ & $<0,05$ & 0,18 \\
\hline Biotita & $<0,05$ & $<0,05$ & $<0,05$ & 0,05 & 0,30 & 0,60 & 0,20 & 1,80 & $<0,05$ & 0,63 & 0,30 & 0,59 & 0,05 \\
\hline Muscovita & ----- & ----- & ----- & ----- & ---- & $<0,05$ & $<0,05$ & 0,10 & ----- & ----- & $<0,05$ & $<0,05$ & $<0,05$ \\
\hline Clinopiroxênio & ----- & ----- & 1,70 & ----- & 0,10 & ----- & ----- & ----- & ----- & ----- & ----- & ----- & ----- \\
\hline Opacos & 1,10 & 0,10 & 1,10 & 0,50 & 0,40 & 0,60 & 0,40 & 0,10 & $<0,05$ & $<0,05$ & 0,05 & 0,32 & $<0,05$ \\
\hline Zircão & $<0,05$ & $<0,05$ & $<0,05$ & $<0,05$ & 0,05 & $<0,05$ & $<0,05$ & $<0,05$ & 0,05 & 0,05 & $<0,05$ & 0,18 & 0,05 \\
\hline Titanita & $<0,05$ & 1,40 & 2,80 & 1,60 & 2,70 & $<0,05$ & 0,05 & $<0,05$ & 1,12 & 0,86 & 0,70 & 0,41 & 1,63 \\
\hline Apatita & 0,40 & 0,20 & $<0,05$ & $<0,05$ & $<0,05$ & $<0,05$ & $<0,05$ & $<0,05$ & 0,05 & $<0,05$ & $<0,05$ & $<0,05$ & $<0,05$ \\
\hline Turmalina & $<0,05$ & $<0,05$ & $<0,05$ & $<0,05$ & $<0,05$ & 0,10 & 0,05 & $<0,05$ & $<0,05$ & $<0,05$ & $<0,05$ & $<0,05$ & $<0,05$ \\
\hline Félsicos & 53,33 & 67,15 & 68,04 & 75,30 & 81,10 & 98,70 & 99,30 & 98,10 & 85,94 & 86,89 & 98,95 & 98,50 & 98,09 \\
\hline Máficos & 46,67 & 32,85 & 31,96 & 24,70 & 18,90 & 1,30 & 0,70 & 1,90 & 14,06 & 13,11 & 1,05 & 1,50 & 1,91 \\
\hline $\mathrm{Q}^{1}$ & 39,75 & 30,38 & 51,44 & 44,62 & 37,98 & 33,84 & 34,94 & 54,03 & 40,71 & 48,77 & 45,38 & 46,24 & 47,48 \\
\hline $\mathrm{P}^{1}$ & 60,00 & 69,40 & 48,06 & 55,11 & 61,65 & 65,35 & 64,35 & 44,55 & 58,32 & 51,12 & 52,55 & 53,42 & 51,83 \\
\hline $\mathrm{A}^{1}$ & 0,09 & 0,07 & 0,29 & 0,07 & 0,12 & 0,71 & 0,60 & 1,22 & 0,93 & 0,06 & 2,02 & 0,32 & 0,69 \\
\hline Total de pontos & 2000 & 2000 & 2000 & 2000 & 2000 & 2000 & 2000 & 2000 & 2000 & 2206 & 2000 & 2000 & 2000 \\
\hline
\end{tabular}

${ }^{1}$ Recalculados a 100\%, *análise geocronológica (Sardinha et al. 2004)

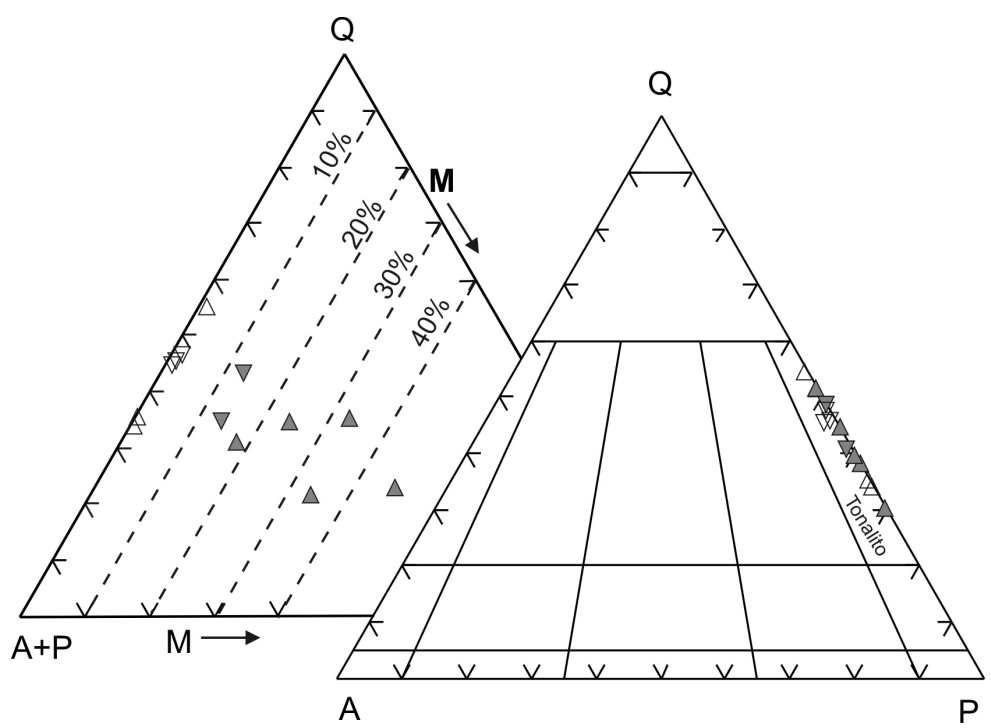

\begin{tabular}{|l|} 
Associação Tonalítica-Trondhjemítica \\
Corpo $\Delta$ Hornblenda-tonalito \\
Norte $\Delta$ Trondhjemito \\
Corpo $\nabla$ Hornblenda-tonalito bandado \\
Sul $\nabla$ Trondhjemito bandado
\end{tabular}

Figura 3 - Diagramas $Q-A-P$ e $Q-(A+P)-M$ da Associação Tonalítica-Trondhjemítica de Canaã dos Carajás. Campos conforme Streckeisen (1976).

diferenciando-se nesse aspecto dos granitóides TTG do TGGRM (Fig. 5a). Além disso, esta associação difere dos granitóides TTG, em geral, inclusive daqueles do TGGRM, pelos seus altos conteúdos de Zr, Y e Ti (Figs. $5 \mathrm{~b}, \mathrm{c}, \mathrm{d})$.

A ATTr exibe moderado fracionamento de elementos terras raras pesados em relação aos leves $[(\mathrm{La} /$ Yb)n de 6,64 a 67,68; Tab. 2], dentro da ampla variação observada em rochas da série TTG arqueanas, que, conforme Martin (1986), têm $5<(\mathrm{La} / \mathrm{Yb}) \mathrm{n}<150$ e conteúdo de $0,3<\mathrm{Ybn}<8,5$ e para Condie $(2005) 25 \pm 15<(\mathrm{La} / \mathrm{Yb})$ $\mathrm{n}<36 \pm 24$. A partir do padrão de elementos terras raras se observa que os tonalitos, com exceção de uma amostra, têm anomalias incipientes ou moderadamente negativa de Eu (Figs. 6a,b), enquanto os trondhjemitos exibem anomalias positivas de $\mathrm{Eu}$, excetuando uma 
Tabela 2 - Análises químicas da Associação Tonalítica-Trondhjemítica de Canaã dos Carajás.

\begin{tabular}{|c|c|c|c|c|c|c|c|c|c|c|c|c|c|c|}
\hline \multirow{3}{*}{$\begin{array}{l}\text { Corpo } \\
\text { Variedades } \\
\text { Amostras }\end{array}$} & \multicolumn{9}{|c|}{ Corpo do Norte da Área } & \multicolumn{5}{|c|}{ Corpo do Sul da Área } \\
\hline & \multicolumn{5}{|c|}{ Tonalitos } & \multicolumn{4}{|c|}{ Trondhjemitos } & \multicolumn{2}{|c|}{ Tonalitos } & \multicolumn{3}{|c|}{ Trondhjemitos } \\
\hline & $\begin{array}{l}\text { AMR } \\
124 \mathrm{~A}\end{array}$ & $\begin{array}{c}\text { AMR } \\
122 \mathrm{C}\end{array}$ & $\begin{array}{c}\text { AMR } \\
121 D^{*}\end{array}$ & $\begin{array}{c}\text { AMR } \\
123\end{array}$ & $\begin{array}{l}\text { AMR } \\
121 \mathrm{~A}\end{array}$ & $\begin{array}{l}\text { AMR } \\
124 \mathrm{~B}\end{array}$ & $\begin{array}{l}\text { AMR } \\
121 \mathrm{E}^{*}\end{array}$ & $\begin{array}{c}\text { AMR } \\
122 \mathrm{~A}\end{array}$ & $\begin{array}{l}\text { AMR } \\
126 \mathrm{~A}\end{array}$ & $\begin{array}{c}\text { AER } \\
068\end{array}$ & $\begin{array}{l}\text { AER } \\
\text { 071C }\end{array}$ & $\begin{array}{l}\text { AMR } \\
191 A^{*}\end{array}$ & $\begin{array}{c}\text { AER } \\
070\end{array}$ & $\begin{array}{c}\text { AER } \\
69 \mathrm{~B}\end{array}$ \\
\hline $\mathrm{SiO}_{2}$ & 55,30 & 64,30 & 66,00 & 66,10 & 67,20 & 75,70 & 76,20 & 76,90 & 80,40 & 71,40 & 73,40 & 77,30 & 78,00 & 79,00 \\
\hline $\mathrm{TiO}_{2}$ & 1,70 & 1,20 & 1,20 & 1,30 & 1,30 & 0,48 & 0,52 & 0,02 & 0,18 & 0,84 & 0,31 & 0,32 & 0,37 & 0,62 \\
\hline $\mathrm{Al}_{2} \mathrm{O}_{3}$ & 13,40 & 13,70 & 14,00 & 13,60 & 14,10 & 13,50 & 14,10 & 13,40 & 11,90 & 13,00 & 12,30 & 13,60 & 12,30 & 12,60 \\
\hline $\mathrm{Fe}_{2} \mathrm{O}_{3}$ & 2,62 & 3,15 & 1,34 & 2,45 & 0,88 & 0,76 & 0,83 & 0,84 & 0,67 & 1,90 & 1,51 & 0,18 & 0,13 & 0,34 \\
\hline $\mathrm{FeO}$ & 8,17 & 4,99 & 3,92 & 3,73 & 2,18 & 0,49 & 0,15 & 0,07 & 0,48 & 1,17 & 1,34 & 0,15 & 0,07 & 0,21 \\
\hline $\mathrm{MnO}$ & 0,12 & 0,06 & 0,07 & 0,07 & 0,09 & 0,03 & 0,02 & $<0,01$ & $<0,01$ & 0,02 & 0,04 & $<0,01$ & $<0,01$ & $<0,01$ \\
\hline $\mathrm{MgO}$ & 4,60 & 1,30 & 1,30 & 1,50 & 1,90 & $<0,1$ & 0,29 & 0,20 & 0,15 & 0,63 & 1,00 & $<0,1$ & $<0,1$ & $<0,1$ \\
\hline $\mathrm{CaO}$ & 7,90 & 4,80 & 5,60 & 4,70 & 5,90 & 1,90 & 2,40 & 1,60 & 0,89 & 3,80 & 3,60 & 2,40 & 2,10 & 2,20 \\
\hline $\mathrm{Na}_{2} \mathrm{O}$ & 3,50 & 4,50 & 4,00 & 4,40 & 4,50 & 4,40 & 5,00 & 4,80 & 4,00 & 4,60 & 3,80 & 4,50 & 4,50 & 4,30 \\
\hline $\mathrm{K}_{2} \mathrm{O}$ & 0,61 & 0,68 & 0,47 & 0,65 & 0,50 & 0,76 & 0,70 & 0,59 & 0,88 & 0,64 & 0,56 & 0,54 & 0,49 & 0,60 \\
\hline $\mathrm{P}_{2} \mathrm{O}_{5}$ & 0,45 & 0,35 & 0,39 & 0,07 & $<0,01$ & 0,02 & $<0,01$ & 0,02 & $<0,01$ & 0,14 & 0,11 & $<0,01$ & $<0,01$ & $<0,01$ \\
\hline $\mathrm{PF}$ & 0,40 & 0,40 & 0,33 & 0,25 & 0,35 & 0,46 & 0,48 & 0,37 & 0,54 & 0,35 & 0,55 & 0,26 & 0,44 & 0,55 \\
\hline Total & 99,68 & 99,99 & 99,06 & 99,18 & 99,15 & 98,65 & 100,72 & 98,83 & 100,16 & 98,62 & 98,67 & 99,39 & 98,53 & 100,56 \\
\hline $\mathrm{Ba}$ & 197 & 277 & $1 / 2$ & 322 & 227 & 279 & 207 & 30 & 411 & 100 & $<10$ & 133 & 126 & 117 \\
\hline $\mathrm{Sr}$ & 258 & 298 & 349 & 312 & 369 & 296 & 320 & 88 & 186 & 289 & 194 & 258 & 238 & 262 \\
\hline $\mathrm{Rb}$ & $<5$ & $<5$ & $<5$ & $<5$ & $<5$ & $<5$ & $<5$ & $<5$ & 20 & $<5$ & $<5$ & $<5$ & $<5$ & $<5$ \\
\hline $\mathrm{Zr}$ & 148 & 391 & 410 & 420 & 459 & 276 & 257 & 91 & 293 & 755 & 343 & 495 & 489 & 685 \\
\hline $\mathrm{Nb}$ & $<5$ & 22 & 33 & 22 & 21 & 9 & 19 & $<5$ & $<5$ & 17 & $<5$ & $<5$ & 14 & 9 \\
\hline $\mathrm{Y}$ & 20 & 38 & 41 & 30 & 23 & 5 & 3 & 16 & 4 & 67 & 31 & 17 & 28 & 15 \\
\hline $\mathrm{Ga}$ & 13 & 25 & 23 & 18 & 16 & 16 & 18 & 22 & 22 & 14 & 14 & 11 & 14 & 16 \\
\hline $\mathrm{V}$ & 304 & 105 & 87 & 69 & 52 & $<10$ & $<10$ & $<10$ & 20 & 53 & 38 & 17 & $<10$ & $<10$ \\
\hline Th & $<5$ & 23 & 20 & 29 & 17 & $<5$ & 32 & 42 & 20 & 8 & $<5$ & $<5$ & $<5$ & $<5$ \\
\hline $\mathrm{La}$ & 8,91 & & 7,61 & 2,89 & & & 1,88 & 11,23 & 4,29 & 7,04 & 3,91 & 5,19 & 13,07 & \\
\hline $\mathrm{Ce}$ & 22,56 & & 15,63 & 4,79 & & & 2,62 & 19,28 & 6,81 & 9,13 & 6,13 & 9,89 & 16,07 & \\
\hline $\mathrm{Nd}$ & 13,20 & & 9,65 & 2,60 & & & 0,70 & 6,63 & 2,16 & 3,46 & 3,34 & 4,55 & 9,56 & \\
\hline $\mathrm{Sm}$ & 2,53 & & 2,53 & 0,70 & & & 0,08 & 1,09 & 0,50 & 0,56 & 1,09 & 0,78 & 1,97 & \\
\hline $\mathrm{Eu}$ & 0,79 & & 0,64 & 0,13 & & & 0,08 & 0,15 & 0,51 & 0,35 & 0,32 & 0,45 & 0,81 & \\
\hline $\mathrm{Gd}$ & 1,76 & & 2,20 & 0,74 & & & 0,09 & 0,75 & 0,46 & 0,51 & 1,20 & 0,71 & 1,59 & \\
\hline Dy & 0,96 & & 1,43 & 0,63 & & & 0,09 & 0,24 & 0,23 & 0,24 & 0,99 & 0,46 & 1,33 & \\
\hline Ho & 0,13 & & 0,25 & 0,12 & & & 0,02 & 0,05 & 0,04 & 0,04 & 0,15 & 0,08 & 0,19 & \\
\hline $\mathrm{Er}$ & 0,27 & & 0,63 & 0,32 & & & 0,04 & 0,11 & 0,11 & 0,10 & 0,37 & 0,14 & 0,55 & \\
\hline $\mathrm{Yb}$ & 0,32 & & 0,51 & 0,21 & & & 0,08 & 0,11 & 0,09 & 0,09 & 0,40 & 0,16 & 0,65 & \\
\hline $\mathrm{Lu}$ & 0,05 & & 0,08 & 0,03 & & & 0,02 & 0,02 & 0,03 & 0,04 & 0,07 & 0,02 & 0,09 & \\
\hline$(\mathrm{La} / \mathrm{Yb}) \mathrm{n}$ & 19,09 & & 10,17 & 9,42 & & & 16,29 & 67,68 & 33,65 & 55,25 & 6,64 & 21,61 & 13,51 & \\
\hline$(\mathrm{La} / \mathrm{Lu}) \mathrm{n}$ & 20,55 & & 9,87 & 11,11 & & & 8,49 & 50,68 & 17,80 & 20,30 & 5,63 & 24,47 & 15,07 & \\
\hline$\left(\mathrm{Eu} / \mathrm{Eu}^{*}\right) \mathrm{n}$ & 1,09 & & 0,81 & 0,55 & & & 2,80 & 0,47 & 3,20 & 1,97 & 0,84 & 1,81 & 1,36 & \\
\hline
\end{tabular}

PF: perda ao fogo, * análise geocronológica (Sardinha et al. 2004)

amostra (Figs. 6a,b). Constatou-se que a ATTr difere da grande maioria das associações TTG, que tendem a apresentar anomalias de Eu incipientes ou moderadamente negativas e, só raramente, anomalias positivas. Como exemplo, há as rochas da Associação Naavala, da parte oriental da Finlândia, descrita por Martin (1987), que apresenta um grupo de rochas da série TTG com anomalias positivas de Eu. A maior parte dos TTGs arqueanos tem maiores teores de ETRL e padrões mais fortemente fracionados de ETR, em comparação com ATTr (Fig. 6c).

Em diagrama multi-elementos (Fig. 7), a ATTr apresenta como característica marcante a presença de anomalias positivas de $\mathrm{Zr}$, Ti e $\mathrm{Y}$, o que não é comum em granitóides TTG, os quais não costumam apresentar anomalias de $\mathrm{Y}$ e $\mathrm{Zr}$ e quase sempre exibem acentuadas anomalias negativas de Ti (Martin 1994, Condie 2005). Em termos do Zr, os TTGs mais antigos do maciço Sete Voltas, do Cráton do São Francisco, constituem uma exceção, pois também apresentam anomalia positiva deste elemento (Martin et al. 1997). Outra característica particular da ATTr é a anomalia negativa de Rb e ausência de anomalia negativa de $\mathrm{Nb}$, feições que a distingui da maioria dos granitóides TTG (Martin et al. 

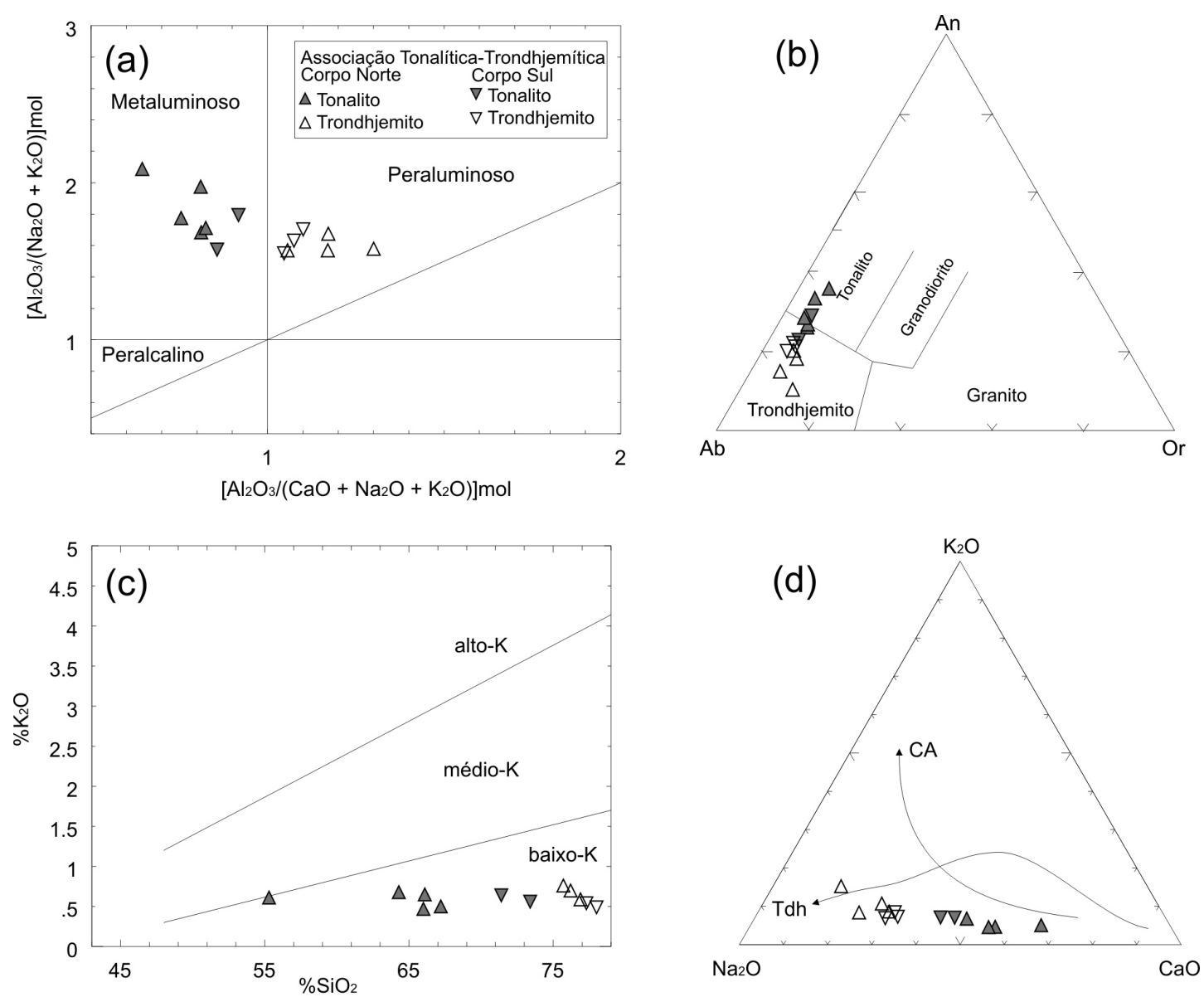

Figura 4 - Diagramas geoquímicos da Associaçãos Tonalitica-Trondhjemítica de Canaã dos Carajás. (a) Diagrama $\left[\mathrm{Al}_{2} \mathrm{O}_{3} /\left(\mathrm{Na}_{2} \mathrm{O}+\mathrm{K}_{2} \mathrm{O}\right)\right] \mathrm{mol}$ vs. $\left[\mathrm{Al}_{2} \mathrm{O}_{3} /\left(\mathrm{CaO}+\mathrm{Na} \mathrm{O}+\mathrm{K}_{2} \mathrm{O}\right)\right] \mathrm{mol}$ (Maniar \& Piccoli 1989); (b) Diagrama Na-Ab-Or normativo (Barker 1979); (c) Diagrama SiO, vs. $\mathrm{K}_{2} \mathrm{O}$ (modificado de Le Maitre et al. 2002); (d) Diagrama $\mathrm{Na} \mathrm{O}_{2} \mathrm{~K}_{2} \mathrm{O}-\mathrm{CaO}$ (trends $\mathrm{CA}=$ cálcioalcalino, Tdh=trondhjemitico, segundo Barker \& Arth 1976).

1997, Martin 1999, Althoff et al. 2000). As anomalias positivas de $\mathrm{Zr}$ e Y são marcantes em todas as amostras da ATTr, enquanto que as anomalias positivas de Ti são mais desenvolvidas nos tonalitos. No diagrama multielementos, a aparente anomalia positiva de Sr (Figs. $7 \mathrm{a}, \mathrm{b})$ reflete o empobrecimento de elementos terras raras leves e não enriquecimento neste elemento. $\mathrm{Na}$ realidade, os conteúdos de $\mathrm{Sr}$ da ATTr são mais baixos do que na maioria dos TTGs (Fig. 7c; cf. Condie 2005), possivelmente devido à retenção de plagioclásio no resíduo de fusão da fonte geradora de seus magmas, o que também é sugerido pelo seu caráter baixo-Al. Também é possível observar que as rochas da ATTr são empobrecidas em $\mathrm{K}$ e Rb em relação às demais associações da série TTG.

\section{DISCUSSÃO}

As particularidades geoquímicas da ATTr e suas implicações As fontes mais comumente admitidas para os magmas TTG são rochas máficas tholeíticas hidratadas, transformadas em granada anfibolitos (Martin 1986, 1994; Martin et al. 1997) ou em hornblenda eclogitos (Condie 2005). A retenção de granada e anfibólio nas rochas fonte parcialmente fundidas é vista como feição fundamental para explicar as principais características geoquímicas das associações TTG, entre elas o acentuado empobrecimento relativo em $\mathrm{Yb}$ e as razões $(\mathrm{La} / \mathrm{Yb}) \mathrm{n}$ muito elevadas. Por outro lado, o caráter alto-Al verificado na maioria dessas associações implica ausência ou restrita retenção de plagioclásio na fonte (Condie 2005). A natureza das fontes e das fases residuais também pode explicar as anomalias negativas de $\mathrm{Nb}$ e Ti e o relativo empobrecimento em Y, elemento que tende a acompanhar os ETRP, observadas nos TTGs mais típicos.

Constatou-se, entretanto, que a associação arqueana estudada, embora corresponda perfeitamente às séries TTG em termos de tipos petrográficos, baixos teores de $\mathrm{K}, \mathrm{Rb}$ e $\mathrm{Yb}$ e razões $(\mathrm{La} / \mathrm{Yb})$ n, diverge notavelmente da maioria destas pelo enriquecimento em $\mathrm{Ti}$, $\mathrm{Zr}, \mathrm{Y}$ e, em certa medida, $\mathrm{Nb}$. Como estes elementos têm mobilidade muito pequena, a hipótese de simples contaminação não pode explicar os teores observados na ATTr, mesmo porque tal contaminação deveria se refletir em enriquecimento em $\mathrm{Rb}$ e $\mathrm{K}$, o que não é observado. Portanto, isso indica que a fonte do magma da ATTr era enriquecida em Ti, Zr, Y e Nb, em comparação às fontes de granitóides TTG dominantes em 

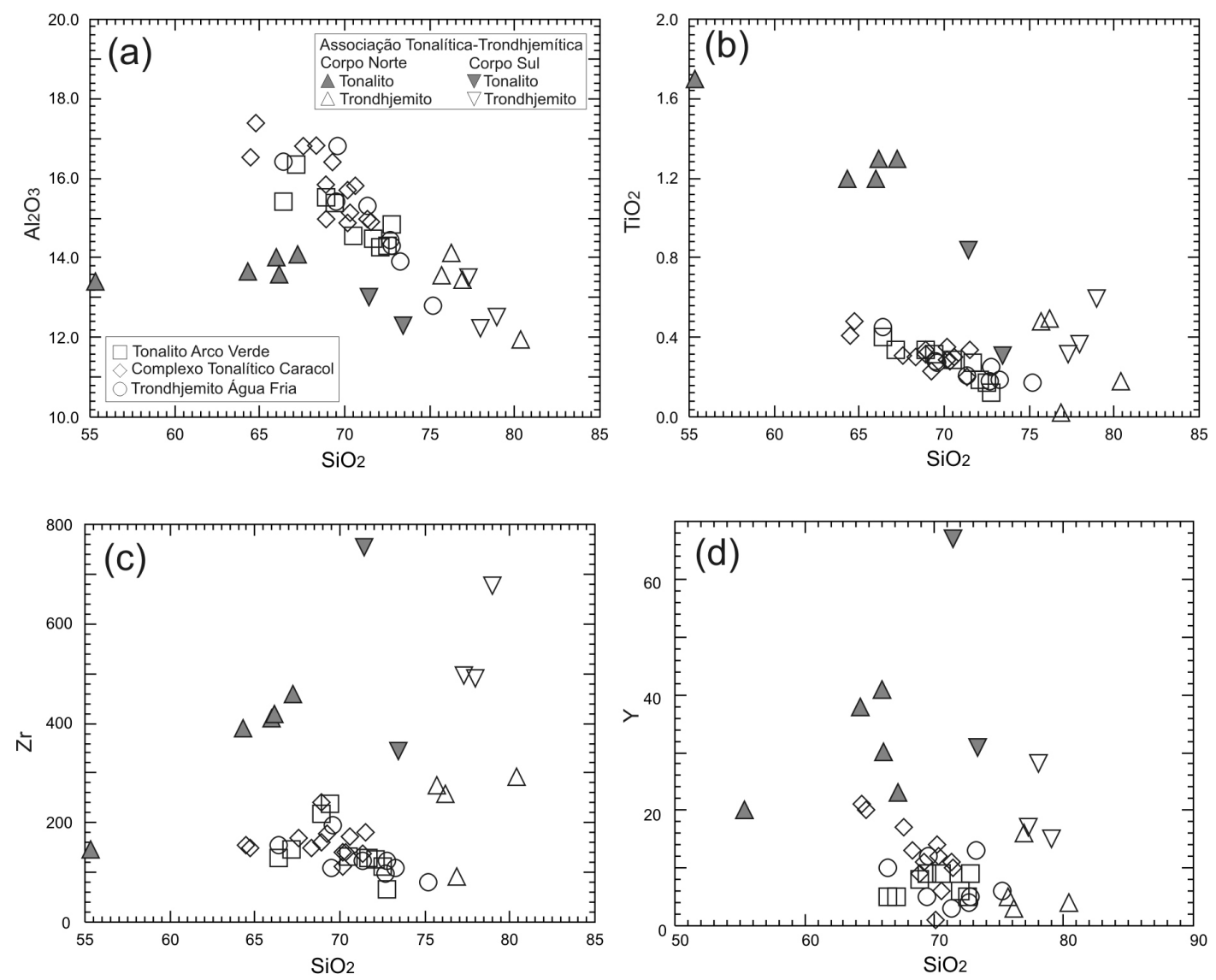

Figura 5 - Diagramas de Harker para (a) $\mathrm{Al}_{2} \mathrm{O}_{3}$, (b) $\mathrm{TiO}_{2}$ (\% em peso), (c) $\mathrm{Zr}$ e (d) $\mathrm{Y}$ (ppm) das amostras da Associação Tonalítica-Trondhjemítica de Canaã dos Carajás, Tonalito Arco Verde (Althoff et al. 2000), Complexo Tonalitico Caracol e Trondhjemito Água Fria (Leite 2001).

terrenos arqueanos (Martin 1994, Althoff et al. 2000, Condie 2005). Uma baixa taxa de fusão também contribuiria para aumentar a concentração de $\mathrm{Zr}, \mathrm{Y}$ e $\mathrm{Nb}$ no magma da ATTr, por serem elementos geralmente incompatíveis que se concentram preferencialmente no líquido durante a fusão (Rollinson 1993). Além disso, a ATTr é do tipo baixo-Al, contrariamente ao que se observa na grande maioria dos TTGs arqueanos.

Tais feições geoquímicas indicam que as fontes e/ou os processos petrogenéticos responsáveis pela formação da ATTr divergem substancialmente daqueles em geral propostos na literatura para explicar a sua origem. As características geoquímicas da ATTr não são compatíveis com processos petrogenéticos envolvendo fontes enriquecidas em granada, pois a retenção de tal fase no resíduo implicaria acentuado empobrecimento em Y e ETRP, contrariamente ao observado na ATTr. $\mathrm{O}$ empobrecimento em elementos terras raras pesados, refletido nas altas razões $(\mathrm{La} / \mathrm{Yb}) n$, e o padrão côncavo dos elementos terras raras pesados (Fig. 6), comuns nas rochas da ATTr, podem ser explicados pelo fracionamento de hornblenda (Martin 1987, Rollinson 1993, Leite 2001) e orto/clinopiroxênio (Rollinson 1993, Leite 2001). Também há indicação de que a fonte da ATTr sofreu fusão parcial, produzindo o seu líquido e um resíduo contendo plagioclásio, pois isso explicaria o caráter baixo-Al e seu relativo empobrecimento em $\mathrm{Sr}$, As anomalias negativas de $\mathrm{Eu}$, presentes em alguns tonalitos da ATTr, podem ser também devidas a fracionamento de plagioclásio (Martin 1987, Rollinson 1993, Leite 2001). Por sua vez, as anomalias positivas de $\mathrm{Eu}$, comuns nos trondhjemitos da ATTr, poderiam ser devidas ao acúmulo de fases enriquecidas em Eu, tais como plagioclásio, ou ao fracionamento de fases (monazita e/ou alanita) que retenham comparativamente mais elementos terras raras leves e pesados do que Eu (Rollinson 1993). Martin (1987) considera que o fracionamento, ainda que em pequeno volume, de alanita, fase que retém grandes quantidades de elementos terras raras leves, associado ao de hornblenda, mineral concentrador preferencial de terras raras pesados, poderia explicar um padrão de elementos terras raras com altas razões $(\mathrm{La} / \mathrm{Yb}) n$, concavidade dos elementos terras raras pesados e anomalia positiva de Eu. Essa última hipótese parece aplicável para a ATTr estudada. O comportamento particular do Ti na ATTr indica igualmente que não pode ter havido retenção expressiva de fases ricas nesse elemento no resíduo de fusão. Isso descarta o fracionamento expressivo de ilmenita no caso da ATTr.

Conclui-se que a ATTr deve ter sido originada a partir da fusão parcial de uma fonte máfica, como admitido para os TTGs, inclusive com base em evidências 

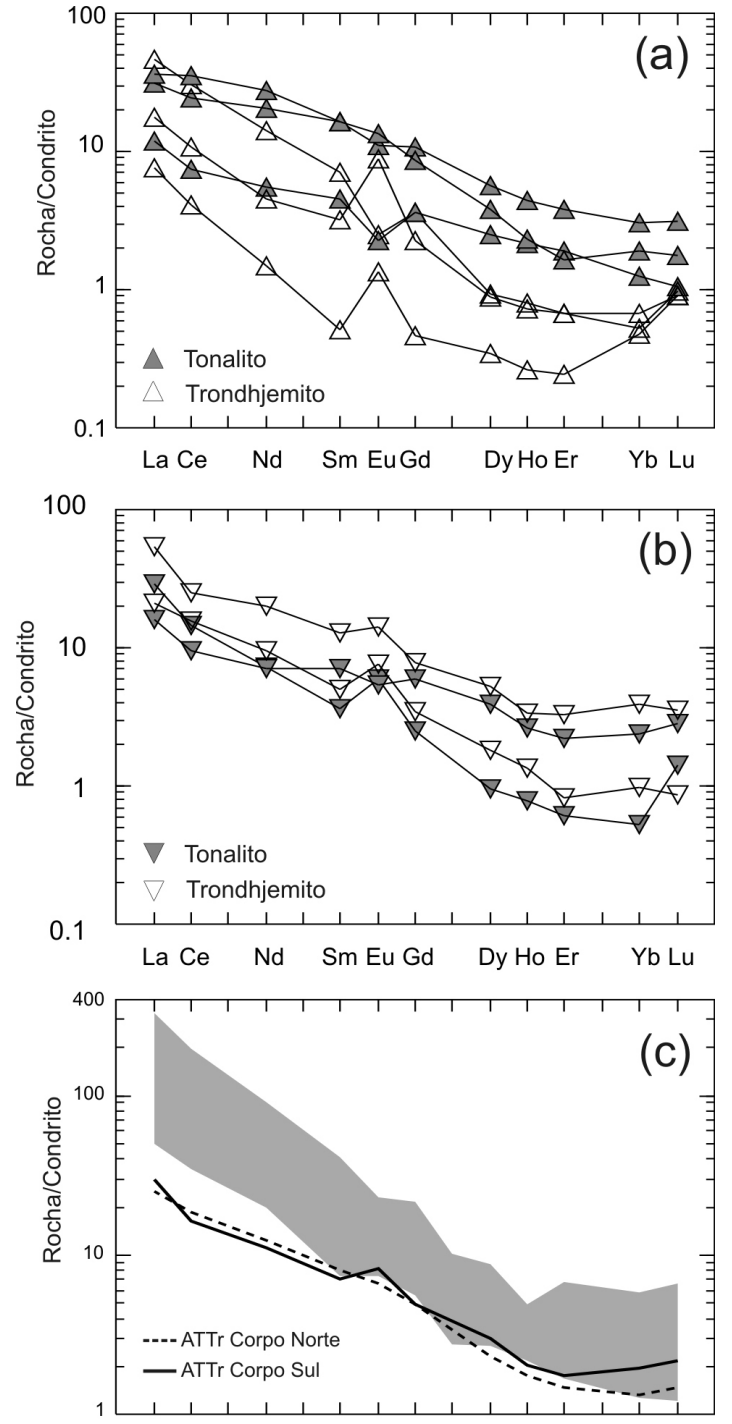

La Ce Pr Nd Sm Eu Gd Tb Dy Ho Er Tm Yb Lu

Figura 6 - Diagramas de padrões de elementos terras raras, valores normalizados pelo condrito de Evensen et al. (1978). (a) Amostras do corpo norte, (b) corpo sul e (c) valores médios das amostras dos respectivos corpos da Associação Tonalítica-Trondhjemítica (ATTr) de Canaã dos Carajás. Campo sombreado representa a composição média dos TTGs arqueanos (Condie 2005); granitóides TTG do Terreno Granito-Greenstone de Rio Maria: Complexo Tonalítico Caracol e Trondhjemito Água Fria (Leite 2001), Tonalito Arco Verde (Althoff et al. 2000); Maciço de Sete Voltas/Bahia (Martin et al. 1997) e TTG Naavala/Finlândia (Martin 1987).

experimentais (Martin 1987, Leite 2001), porém as características mineralógicas e geoquímicas dessa fonte devem diferir substancialmente daquelas da qual derivou a maioria das associações TTG arqueanas. Uma alternativa seria admitir que a ATTr estudada tenha sido originada a partir da fusão parcial de gabros tholeíticos continentais, deixando como resíduo clinopiroxênio + plagioclásio \pm olivina (Barker 1979). Além disso, os padrões de ETR da ATTr indicam influência de hornblenda durante a sua evolução, podendo-se admitir que houve sua retenção no resíduo de fusão (gabros hidratados?) ou por fracionamento durante a cristalização do magma formador da ATTr.

Relações entre tonalitos e trondhjemitos da associação estudada Os tonalitos e trondhjemitos do corpo sul ocorrem intimamente associados, formando bandas alternadas que exibem feições deformacionais coincidentes e grande afinidade mineralógica e geoquímica. Embora só tenha sido datada uma amostra de trondhjemito (Sardinha et al. 2004), é lógico admitir que ambas as rochas sejam cogenéticas e muito provavelmente comagmáticas, tendo a mesma idade. No corpo norte, tonalitos e trondhjemitos ocorrem em blocos alternados, sem relações claras entre eles, mostram maior contraste geoquímico e mineralógico e não foi possível definir sua idade. $\mathrm{Na}$ ausência de datações do corpo norte, pode se questionar se os dois corpos são efetivamente contemporâneos e cogenéticos. Embora não se possa dar uma resposta conclusiva a essa pergunta, a grande similaridade geoquímica entre as rochas dos dois corpos fortalece muito essa interpretação. Portanto, assume-se que as rochas de ambos os corpos da ATTr sejam contemporâneas e derivem de fontes e processos petrogenéticos similares.

No caso do corpo norte, em particular, seria válido especular ainda sobre a hipótese de os trondhjemitos serem oriundos da fusão parcial dos tonalitos com os quais se associam. Martin et al. (1997) apresentam exemplo de TTGs arqueanos no maciço Sete Voltas, em que admitem que os TTGs mais antigos geraram por fusão parcial uma associação trondhjemítica-granodiorítica mais jovem, que forma atualmente a maior parte das rochas expostas no corpo. Essa associação mais jovem é enriquecida em $\mathrm{K}$ e outros elementos incompatíveis em relação aos TTGs mais antigos e segue o trend das associações cálcio-alcalinas clássicas em diagrama K-Na-Ca. Ora, os trondhjemitos da ATTr de Canaã dos Carajás não mostram evidência geoquímica de enriquecimento em elementos incompatíveis (Tab. 2; Fig. 7). O comportamento de $\mathrm{K}$ e $\mathrm{Rb}$, ambos elementos em conteúdos extremamente baixos tanto nos tonalitos quanto nos trondhjemitos da ATTr, ilustra bem essa afirmativa. Portanto, as evidências disponíveis não favorecem a hipótese de geração dos trondhjemitos a partir da fusão parcial dos tonalitos e sim uma vinculação entre os mesmos por processos de cristalização fracionada.

Ambiente tectônico da região estudada e origem da ATTr O modelo clássico para geração de granitóides arqueanos da série TTG admite que a mesma se deu em ambiente de subducção (Martin 1986, 1987, 1994), Entretanto, Leite (2001) considera que a primeira geração $(2,95 \mathrm{Ga}-2,91 \mathrm{Ga})$ de granitóides da série de TTG no TGGRM ocorre associada a uma tectônica vertical (sagducção), de modo análogo ao que Choukroune et al. (1997) propõem para a geração de granitóides TTG 

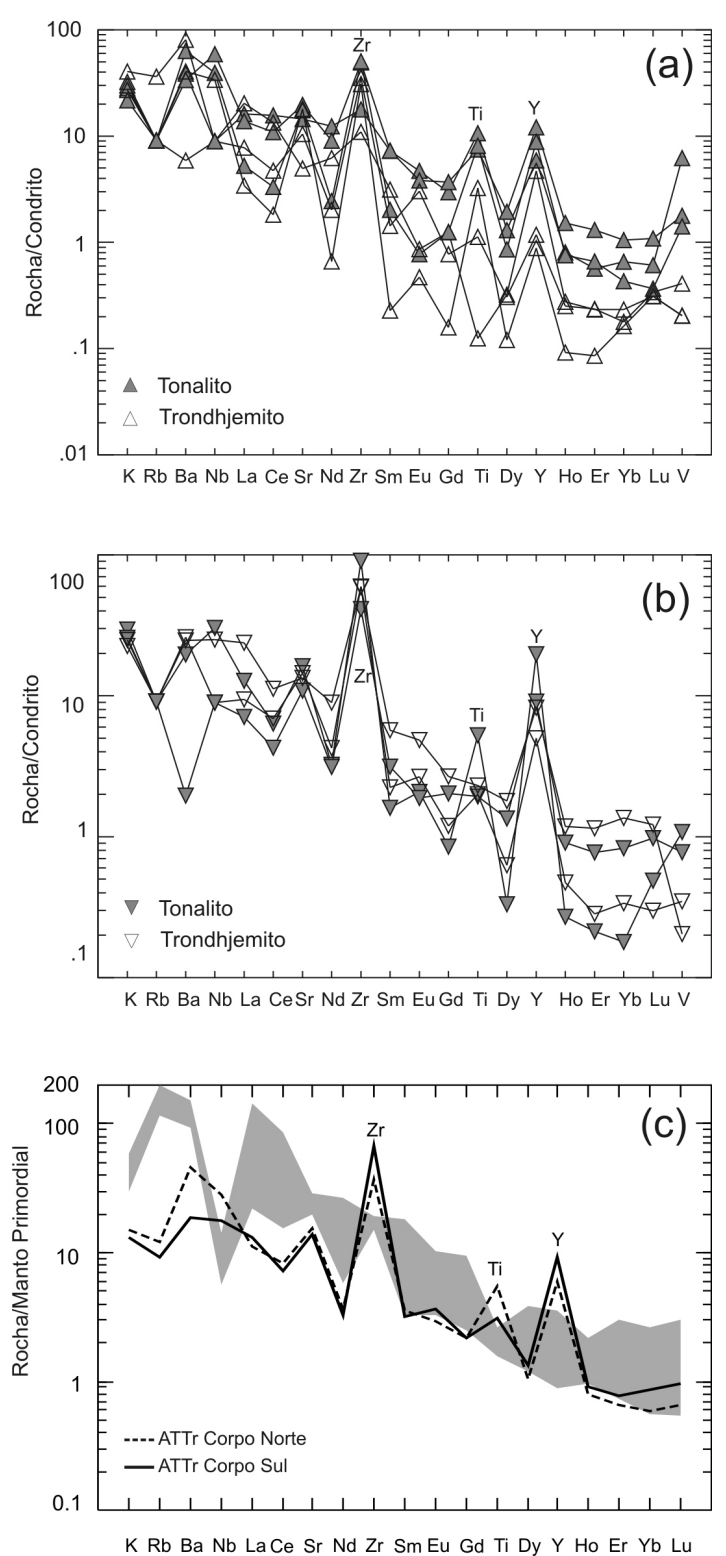

Figura 7 - Diagramas multi-elementos, valores normalizados em relação ao manto primordial (Taylor \& McLennan 1985). (a) Amostras do corpo norte, (b) corpo sul e (c) valores médios das amostras dos respectivos corpos da Associação Tonalítica-Trondhjemítica (ATTr) de Canaã dos Carajás. Campo sombreado representa a composição média dos TTGs arqueanos (Condie 2005); granitóides TTG do Terreno Granito-Greenstone de Rio Maria: Complexo Tonalítico Caracol e Trondhjemito Água Fria (Leite 2001), Tonalito Arco Verde (Althoff et al. 2000); Maciço de Sete Voltas/ Bahia (Martin et al. 1997) e TTG Naavalal Finlândia (Martin 1987).

no Cráton Dharwar na Índia. Althoff et al. (2000) acreditam que a gênese dos granitóides da série TTG do TGGRM, que ocorreu por volta de $2,96 \mathrm{Ga}$, foi associada a um regime tectônico intermediário entre aqueles controlados por processos de subducção e sagducção.
Condie (2005) admite que TTGs alto-Al podem ter sido gerados por fusão parcial de crosta inferior em sistemas de arco ou em zonas de raiz de platôs oceânicos.

As hipóteses de regimes tectônicos envolvendo ambiente de subducção não parecem capazes de explicar a geração do magma TTG da ATTr $(2750 \pm 3 \mathrm{Ma}$, $2765 \pm 39$ Ma, Sardinha et al. 2004), porque neste período se dá na Bacia Carajás a geração de rochas metavulcânicas máficas do Supergrupo Itacaiúnas (2732 \pm 3

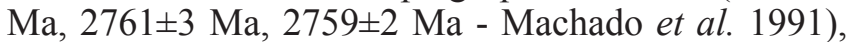
interpretadas como relacionadas a um rifte continental (Gibbs et al. 1986) e pouco mais tarde ou concomitantemente, tanto na Bacia Carajás quanto no domínio de transição entre ela e o TGGRM, formação de granitos subalcalinos tipo-A, exemplificados pelo Complexo Granítico Estrela (2763 \pm 7 Ma, Barros et al. 2001), e granitos Serra do Rabo (2743 \pm 1 , Sardinha \& Barros 2002) e Planalto (2747 $\pm 2 \mathrm{Ma}$ - Huhn et al. 1999, $2734 \pm 4$ Ma Sardinha et al. 2004), além dos granitos supostamente perluminosos e 'colisionais' da Suíte Plaquê (2736 \pm 24 Ma, Avelar et al. 1999). Tais evidências indicam a existência no Neoarqueano de ambiente continental intra-placa na região de Canaã dos Carajás e na Província Mineral de Carajás. A hipótese de ambiente tectônico continental para a região é reforçada pela existência na mesma do Complexo Granulítico Pium, datado em cerca de 3,0 Ga com metamorfismo em torno de 2,85 Ga (Pidgeon et al. 2000). Nesse ambiente não haveria a possibilidade de fusão de crosta oceânica subductada ou de cunha de manto sobrejacente à placa subductante para gerar o magma TTG. Porém, o acentuado espessamento crustal associado à formação do Cinturão de Cisalhamento Itacaiúnas, ligado ao elevado gradiente geotérmico prevalente no Arqueano, poderia levar à fusão parcial de rochas máficas tholeíticas residentes na base da crosta, gerando assim o magma formador da ATTr.

O grande volume de magma gerado por volta de 2,75-2,70 Ga no norte da Província Mineral de Carajás, indica que no Arqueano havia uma anomalia térmica expressiva nas circunvizinhanças de Canaã dos Carajás. Como o volume dos corpos da ATTr é pequeno, é provável que tenha ocorrido para geração do seu magma uma fusão parcial, em pequena escala, de rochas máficas de ambiente continental, com características químicas similares aos basaltos da Bacia do Paraná, que podem ser enriquecidos em $\mathrm{TiO}_{2}, \mathrm{Zr}$ e Y (respectivamente, 3,95\%, $398 \mathrm{ppm}$ e $42 \mathrm{ppm}$; Wilson 1989, Tabela 10.3).

CONCLUSÃO A ATTr é formada por dois pequenos corpos os quais eram cartografados como parte do Complexo Xingu ou Granito Plaquê. Petrograficamente suas rochas são restritas ao campo dos tonalitos (QAP). Porém em função do volume de minerais máficos, são divididos em tonalitos e trondhjemitos, os quais seguem o trend das rochas da série cálcio-alcalina tonalítica-trondhjemítica de baixo potássio (Lameyre \& Bowden 1982). O principal mineral máfico é a hornblenda nos tonalitos e biotita nos trondhjemitos. Os tonalitos 
e trondhjemitos são metaluminosos e peraluminosos, respectivamente. São rochas cálcio-alcalinas empobrecidas em $\mathrm{K}_{2} \mathrm{O}$, acompanham o trend trondhjemítico no diagrama $\mathrm{K}_{2} \mathrm{O}-\mathrm{Na}_{2} \mathrm{O}-\mathrm{CaO}$ e no diagrama normativo Albita-Anortita-Ortoclásio situam-se nos campos de tonalitos e trondhjemitos.

As características da ATTr mostram que ela difere dos granitóides TTG típicos e daqueles presentes no Terreno Granito-Greenstone. Isto em função dos altos teores de Zr, Ti e Y e, no caso dos TTGs do Terreno Granito-Greenstone de Rio Maria, também porque as rochas da ATTr são mais empobrecidas em $\mathrm{Al}_{2} \mathrm{O}_{3}$.

$\mathrm{O}$ magma da ATTr deriva da fusão parcial de rochas máficas, com características mineralógicas e geoquímicas substancialmente distintas daquelas que originaram a maioria das associações TTG arqueanas. Admite-se que a fusão parcial de gabros tholeíticos continentais, em pequena escala, produziu o magma da ATTr e um resíduo à base de clinopiroxênio + plagio- clásio \pm olivina. A hornblenda, por meio de sua retenção no resíduo de fusão ou por fracionamento durante a cristalização, também influenciou a evolução do magma da ATTr. O fracionamento da alanita pode ser uma das explicações para as anomalias positivas de $\mathrm{Eu}$, presentes em algumas amostras da ATTr.

Agradecimentos Aos pesquisadores do Grupo de Pesquisa Petrologia de Granitóides (GPPG-CG-UFPA) pelo apoio nas diversas etapas deste trabalho; ao CNPq pela concessão da bolsa de mestrado ao primeiro autor e pelo apoio ao desenvolvimento da pesquisa (55.0739/01-7, 476075/03-3); ao Centro de Geociências (CG-UFPA) pelo suporte técnico; ao Químico Natalino Valente pela realização das análises de $\mathrm{FeO}$; aos revisores da $\mathrm{RBG}$ pelas sugestões ao manuscrito. Este artigo é uma contribuição para o projeto PRONEX/CNPQ (Proj. 103/98 - Proc. 66.2103/1998-0).

\section{Referências}

Althoff F. J., Barbey P., Boullier A.-M. 2000. 2.8-3.0 Ga plutonism and deformation in the SE Amazonian craton: the Archean granitoids of Marajoara (Carajás Mineral Province, Brazil). Precam. Res. 104:187-206.

Araújo O.J.B., Macambira E.M.B., Vale A.G., Oliveira J.R., Silva Neto C.S., Costa E.J.S., Santos A., Pena Filho J.I.C., Neves A.P., Jorge João X.S., Costa J.B.S. 1994. Primeira integração das investigações geológicas do Programa Grande Carajás na região SSE do Estado do Pará. In: SBG, Simp. Geol. Amaz., 4, Belém, Anais, p. 299-306.

Araújo O.J.B. \& Maia R.G.N. 1991. Programa Levantamentos Geológicos Básicos do Brasil, Serra dos Carajás. Folha SB.22-Z-A. Estado do Pará. Escala 1:250.000. Brasília, DNPM/CPRM, 136p.

Avelar V.G., Lafon J.M., Correia Jr. F.C., Macambira E.M.B. 1999. O Magmatismo arqueano da região de TucumãProvíncia Mineral de Carajás: novos resultados geocronológicos. Rev. Bras. Geoc. 29(2):454-460.

Barker F. 1979. Trondhjemites: definition, environment and hypotheses of origin. In: F. Barker (ed.) Trondhjemites, dacites and related rocks. Amsterdam, Elsevier, p. 1-12.

Barker F. \& Arth J.G. 1976. Generation of trondhjemitic-tonalitic liquids and Archaean bimodal trondhjemite-basalt suites. Geology, 4:596-600.

Barros E.M., Sardinha A.S., Barbosa J.P.O., Krimski R., Macambira M.J.B. 2001.Pb-Pb and U-Pb zircon ages of Archean syntectonic granites of the Carajás Metallogenic Province, northern Brazil. In: Sociedad Geológica de Chile, Simposio Sudamericano de Geologia Isotópica, 3, Santiago, Anais, CD-ROM.

Choukroune P., Ludden J.N., Chardon D., Calvert A.J., Bouhallier H. 1997. Archean crustal growth and tectonics processes: a comparison of the Superior Province, Canada and the Dharwar Craton, India. In: J.P. Burg \& M. Ford (eds.) Orogeny Through Time. Geological Society Special Publish, 121, London, p. 63-98.
Condie K.C. 1993. Chemical composition and evolution of the upper continental crust: contrasting results from surface samples and shales. Chem. Geol., 104:1-37.

Condie K.C. 2005. TTGs and adakites: are they both slab melts? Lithos, 80:33-44.

Costa J.B.S., Araújo O.J.B., Santos A., Jorge João X.S., Macambira M.J.B., Lafon J.-M. 1995. A província mineral de Carajás: aspectos tectono-estruturais, estratigráficos e geocronológicos. Bol. Mus. Par. Emílio Goeldi - Série Ciências da Terra, 7:199-235.

CPRM - Companhia de Pesquisa de Recursos Minerais. 2004. Carta Geológica do Brasil ao Milionésimo: Folha SB.22, Araguaia. CPRM, CD-ROM.

Dall'Agnol R., Rämö O.T., Magalhães M.S., Macambira M.J.B. 1999. Petrology of the anorogenic, oxidised Jamon and Musa granites, Amazonian Craton: implications for the genesis of Proterozoic A-type granites. $\mathrm{Li}$ thos, 46:431-462.

Dall'Agnol R., Souza Z.S., Althoff F.J., Barros C.E.M., Leite A.A.S., Jorge João X.S. 1997. General aspects of the granitogenesis of the Carajás metallogenic province. In: Superitendência de Geologia e Recursos MineraisSGRM, Intern. Symp. on Gran. and Associated Mineralizations, 2, Salvador, Excursions Guide, p.135-161.

DOCEGEO - Rio Doce Geologia e Mineração. 1988. Revisão litoestratigráfica da Província Mineral de Carajás. In: SBG, Cong. Bras. Geol., 35, Belém, Anais, p. 11-54.

Evensen N.M., Hamilton P.T., O’nions R.K. 1978. Rare earth abundances in chondritic meteorites. Geochim. Cosmochim. Acta, 39:55.64.

Gibbs A.K., Wirth K.R., Hirata W.K., Olszewski W.J. 1986. Age and composition of the Grão Pará Group Volcanics, Serra dos Carajás. Rev. Bras. Geoc., 16:201-211.

Gomes A.C.B. 2003. Geologia, petrografia e geoquímica dos granitóides de Canaã dos Carajás, SE do Estado do Pará. Belém, Dissertação de Mestrado, Centro de Geociências, Universidade Federal do Pará, 164 p. 
Huhn S.R.B., Macambira M.J.B., Dall'Agnol R. 1999. Geologia e Geocronologia $\mathrm{Pb} / \mathrm{Pb}$ do Granito Alcalino Arqueano Planalto, Região da Serra do Rabo, Carajás-PA. In: SBG, Simp. Geol. Amaz., 6, Manaus, Boletim de resumos expandidos, p. 463-466.

Lameyre J. \& Bowden P. 1982. Plutonic rock type series: discrimination of various granitoid series and related rocks. Jour. Volcan. Geother. Res., 14:169-186.

Le Maitre R.W., Bateman P., Dudex A., Keller J., Lameyre J., Le Bassabine P.A., Schmid R., Sorensen H., Streckeisen A., Woolwy R.A., Zannettin B. 2002. Igneus rock. A classification and glossary of terms. Cambridge, Cambridge University Press, $236 \mathrm{p}$.

Leite A.A.S. 2001. Geoquímica, petrogênese e evolução estrutural dos granitóides arqueanos da região de Xinguara, Se do Cráton Amazônico. Tese de Doutoramento, Centro de Geociências, Univ.Federal do Pará, 209p.

Leite A.A.S., Dall'Agnol R., Macambira M.J.B., Althoff F.J. 2004. Geologia e geocronologia dos granitóides arqueanos da região de Xinguara-PA e suas implicações na evolução do Terreno Granito-Greenstone de Rio Maria, Cráton Amazônico. Rev. Bras. Geoc., 34(4):447-458.

Lima F.D. 2002. Evolução tectônica da terminação leste da Falha Carajás, sul do Estado do Pará. Dissertação de Mestrado, Centro Geociências, Univ. Federal Pará, 98p.

Lima F.D. \& Pinheiro R.V.L. 2001. Formação Gorotire: considerações sobre uma unidade siliciclástica particular da Serra dos Carajás-PA. In: N.J. Reis \& M.A.S. Monteiro (eds.) Contribuições à Geologia da Amazônia, 2, SBG, p.201-224.

Macambira M.J.B. \& Lafon J.M. 1995. Geocronologia da Província Mineral de Carajás, síntese dos dados e novos desafios. Bol. Mus. Par. Emílio Goeldi-Série Ciências da Terra, 7:263-288.

Macambira M.J.B. \& Lancelot J.R. 1996. Time constraints for the formation of the Archean Rio Maria crust, southeastern Amazonian Craton, Brazil. Intern. Geol. Rev. 38:1134-1142.

Machado N., Lindenmayer Z.G., Krogh T.E., Lindenmayer D. 1991. U-Pb geochronology of Archean magmatism and basement reactivation in the Carajás area, Amazon shield, Brazil. Precam. Res., 49:329-354.

Maniar P.D. \& Piccolli P.M. 1989. Tectonic discrimination of granitoids. Geol. Soc. Amer. Bul., 97:635-643.

Martin H. 1986. Effect of steeper Archaean geothermal gradient on geochemistry of subduction - zone magma. Geology, 14:753-756.

Martin H. 1987. Petrogenesis of Archaean trondhjemites, tonalites and granodiorites from eastern Finland: major and trace element geochemistry. Jour. Petrol., 28:921-953.

Martin H. 1994. The Archaean grey gneisses and the gneisses of continental crust. In: K.C. Condie (ed.) Developments in Precambrian Geology. Archaean crust evolution, 11, Amsterdam, Elsevier, p. 205-259.

Martin H. 1999. Adakitic magmas: modern analogues of Archaean granitoids. Lithos, 46:411-429.

Martin H., Peucat J.J., Sabaté J.C., Cunha J.C. 1997. Crustal evolution in the Archaean of South America: example of the Sete Voltas Massif, Bahia State, Brazil. Precam. Res., 82:35-62.
Nogueira A.C.R. 1995. Análise faciológica e aspectos estruturais da Formação Águas Claras, região central da Serra dos Carajás - PA. Dissertação de Mestrado, Centro de Geociências, Universidade Federal do Pará, 167 p.

Pidgeon R.T., Macambira M.J.B., Lafon J.M. 2000. Th-U-Pb isotopic systems and internal structures of complex zircons from an enderbite from the Pium Complex, Carajás Province, Brazil: evidence for the ages of granulite facies metamorphism and the protolith of the enderbite. Chem. Geol., 166:159-171.

Pimentel M.M. \& Machado N. 1994. Geocronologia U-Pb do Terreno Granito-Greenstone de Rio Maria, Pará. In: SBG, Cong. Bras. Geol., 38, Camboriú, Boletim de Resumos Expandidos. v. 2, p. 390-391.

Pinheiro R.V.L. 1997. Reactivation history of the Carajás and cinzento Strike-slip Systems, Amazon, Brazil. Tese de Doutoramento, University of Durhan, 408 p.

Rolando A.P. \& Macambira M.J.B. 2003. Archean crust formation in Inajá range area, SSE of Amazonian Craton, Brazil, basead on zircon ages and Nd isotopes. In: Simp. Sulamericano Geo. Isotópica, 4,Salvador,Atas, CD-rom.

Rolando A.P., Macambira M.J.B., Barros C.E.M. 2004. Geocronologia dos granitóides sin a tardi-tectônicos $(2,88$ 2,85 Ga) do sul do Terreno Granito-Greenstone de Rio Maria, Província Mineral de Carajás. In: SBG, Congresso Brasileiro de Geologia, 42, Araxá, Atas, CD-ROM.

Rollinson H.R. 1993. Using geochemical data: evolution, presentation, interpretation. Longman Scientific \& Technical, New York, 352 p.

Sardinha A.S. \& Barros C.E.M. 2002. Geologia, geoquímica e geocronologia do Granito Serra do Rabo, Província Mineral de Carajás. In: SBG, Cong. Brás. de Geol., 41, João Pessoa, Anais, p .472.

Sardinha A.S., Dall'Agnol R., Gomes A.C.B., Macambira M.J.B., Galarza M.A. Geocronologia Pb-Pb E U-Pb em zircão de granitóides arqueanos da região de Canaã dos Carajás, Província Mineral de Carajás. In: SBG, Congr. Brasileiro de Geologia, 42, Araxá, Atas, CD-ROM.

Souza Z.S. 1994. Geologia e petrogênese do Greenstone belt: Identidade: implicações sobre a evolução geodinâmica do terreno granito- "greenstone" de Rio Maria, SE do Pará. Tese de Doutoramento, Centro de Geociências, Universidade Federal do Pará, v. 1 e 2, 624 p.

Souza Z.S., Protel A., Lafon J.M., Althoff F.J., Pimentel M.M., Dall'Agnol R., Oliveira C.G. 2001. Nd, Pb and isotopes in the Identidade Belt, na Archaean greenstone belt of the Rio Maria region (Carajás Province, Brazil): implications for the Archaean geodynamic evolution of the Amazonian Craton. Precam. Res., 109:293-315.

Streckeisen A.L. 1976. To each plutonic rock its proper name. Earth Sci. Rev., 12:1-33.

Taylor S.R. \& McLennan S.M. 1985. The continental crust: Its composition and evolution. Oxford, Backwell Scientific, $321 \mathrm{p}$.

Wilson M. 1989. Igneous Petrogenesis: A global tectonic approach. London, Unwin Hyman, 466 p.

Manuscrito AE-003/2006

Recebido em 17 janeiro de 2006 Aceito em 28 de maio de 2007 